\title{
Development of Music Dictation Learning Materials in Music Study Program Majoring in Sendratasik FBS Universitas Negeri Padang
}

\author{
Jagar Lumbantoruan ${ }^{1, *}$ \\ ${ }^{1}$ Jurusan Sendratasik, Fakultas Bahasa dan Seni Universitas Negeri Padang, Sumatera Barat, Indonesia \\ * Coresponding Email Jagartoruan@fbs.unp.ac.id
}

\begin{abstract}
This research aims to reveal the development of Music Dictation learning materials that include (1) the concept of music dictation, (2) content levels, and (3) material development principles. The research method used is qualitatively. The results include: (a) understanding of learning materials and scope, (b) The content levels of learning materials are: facts, concepts, procedures, and principles, (c) Principles of development, namely: (a) conformity, (b) conformity, (c) continuity, and (d) compactness. The packaging of learning materials is tailored to the academic characteristics of the student, the student's learning style, and the profile of the music study program.
\end{abstract}

Keywords: Development, learning materials, music dictation

\section{INTRODUCTION}

In the world of education and learning, curriculum as content, processes, and activities. With regard to content, curriculum is the scope of subject topics and tasks given to work on. As a process that is the form and pattern of activities carried out. While learning activities are instructions on approaches, strategies, methods, techniques and learning tactics.

The topic of the lesson is the content of learning in the curriculum that must be mastered by students in accordance with the basic competencies in order to achieve competency standards from each field of study. The learning material component is the most important part of the learning activity, and can even be said to be the core of the implementation of learning. Therefore, learning materials are distinguished by nature and goals, namely: (a) knowledge, (b), attitude, and (c) skills. Knowledge is referenced in the information stored in the mind, must be mastered by the learner, so that where necessary, it can be re-disclosed. Attitudes point to a person's tendency to act, behave, act in accordance with universal values and norms. Skills refer to physical and non-physical actions that are critical thinking to achieve the goal.
In addition to nature and object, [1] explains that learning materials are categorized into four parts, namely: (a) facts, i.e. the nature of an object that can be captured by the human senses. For example, music media is sound; sound according to time and space. (b) Concept, i.e. miniature abstraction of a group of objects or properties. For example, notation is the epitome of rhythmic and melodic tone. (c) Procedure, is a systematic step, way, or step to know something. For example, how to transcribe musical sounds is done with a series of activities, namely listening exercises, identifying rhythm sounds, intervals, and melodies that are listened to and then transcribed. (d) The principle, i.e. the relationship between two or more empirically tested concepts, in the form of generalizations that can then be drawn into principle. For example, listening and identifying sounds in Music Dictation learning as the basis for similar courses.

Music Dictation is one of the curriculum, content, and learning instruction for students in music studies programs. The content of the lesson is rhythm, interval, and melody and its elements. Learning instruction is an exercise in listening, identifying, and transcribing the rhythm, intervals, and melodies that are heard. The formulation of the purpose of learning is to skillfully transcribe the rhythms, intervals, and melodies that are listened to into the form of writing. Forms of learning experience, namely: (1) hearing 
exercises, (2) identifying exercises, and (3) transcription exercises. Learning strategies are exercises and assignments

Many problems arise with regard to Music Dictation, namely: (a) students have a lot of difficulty following learning, (b) learning dictation music too early because given in the first semester, (c) the design of learning materials less considering the characteristics of academic abilities of students who are in the beginner's state of knowledge and skills rhythm, intervals, and melodies, (d) the characteristics of knowledge and skills of Music Dictation is demanding cognitive surgery skills, (e) rhythm material, intervals, and melodies have not been arranged according to standard principles.

The design of the Music Dictation learning materials above, side by side with the main goals and objectives, learning experiences, methods, and packaging shapes. The packaging forms visuals, audio, and print shapes. The visual shapes of rhythms, intervals, and melodies are symbols of representations of the sound of notation and tone. The audio form is a recording of notes or tones. The printed form is a printed book containing rhythm theory, intervals, and melodies. Considerations of packaging are based on: (a) conformity to learning purposes, (b) simplicity, (c) material organizing, (d) instructions on how to use. [2] suggests that the design of learning materials has four components, namely: (a) purpose, (b) teaching materials, learning activities or experiences, (c) organization or composition of subject matter, and (d) evaluation. In line with the above opinion, the development of musical material is pointing to the initial understanding and ability that students have. In addition, it is also the first step in assisting learning activities relevant to the level of development [3]; [4]; [5].

Based on the results of analysis on learning achievements in accordance with KKNI, it has not increased significantly. Indications of the low achievement of learning are known through lecture activities in serum courses, namely: (1) Transcription of Music Analysis, (2) Choir, (3) Practice of Major Vocal Instruments, Instrumentals. In response to these conditions, research is needed to focus on the design and development of Music Dictation learning materials in accordance with the principles of learning material development based on several aspects, namely: (1) conformity, (2) order, (3) continuity, and (4) compactness. Thus the topic of this research is: Development of Music Dictation Learning Materials in the Music Study Program of Sendratasik FBS State University Padang.

\section{RESEARCH METHODOLOGY}

This research approach is a descriptive approach to analytics. The choice of these qualitative types in line with such thinking [6] suggests that qualitative research will produce descriptive data in the form of written or oral words, or data in the form of observed behavior. Such observations should be made thoroughly. [7] suggests that qualitative research is an effort to provide interpretation and perception of the objects studied. Qualitative analysis is conducted thoroughly and in a natural environment.

This research method is a descriptive method because (1) this research is intended to describe systematically, factually, and accurately about certain facts and properties as is the case at the time of the study, (2) this research tries to describe the development of learning materials based on the achievements, objectives, learning experiences expected and carried out; types and arrangements of learning materials. The choice of method is in line with the opinion [8] which says that descriptive methods deal with words, not numbers.

The object of this research is the Development of Music Dictation Learning Materials in the Music Study Program of Sendratasik FBS State University Padang, including: (1) Rhythm material packaging and development, (2) Interval and development material packaging, (3) Melodic material packaging and development.

\section{DISCUSSION}

\subsection{Understanding learning materials}

The overall success of learning depends largely on the success of lecturers designing learning materials. Learning Materials are essentially an integral part of the Syllabus, namely planning, prediction and projection of what to do and expect during and after learning activities. In general, it can be argued that learning materials are knowledge, skills, and attitudes that students must master in order to meet the established competency standards.

Learning materials occupy a very important position of the entire curriculum, which must be prepared in order for the implementation of learning to achieve its goals. These goals must be in accordance with the goals and achievements of learning that must be achieved by students. That is, the specified material aims to provide the widest learning experience so that basic competency and competency standards can be achieved. To become clearer in identifying learning materials whether it includes cognitive aspects (facts, concepts, principles, and procedures), affective aspects (performing actions according to value), and psychomotor aspects of physical and non-physical or cognitive surgery.

Factually, rhythms, intervals, and melodies sound according to space and time. Conceptually that rhythm is a motion in time built by different units of notes in short, moving according to duration. Interval, i.e. the distance of two different high-low tones according to the frequency. 
Melodies, are motions in space built by units of different tones of short-length, high-low, and duration [9] [P: 103]; [10] [P: 47]. Procedurally, that way of studying rhythm, intervals, and melodies is done through hearing, identification, and transcription exercises. Principally, to understand rhythms, intervals, and melodies based on understanding pulses, beats, and meters.

Music Dictation learning materials are effectively organized in three parts, namely: rhythm, interval, and melody [11] [2013]; [12] [P: 40]; [13] [2016). Rhythm organizations are notation, beat, tempo, meter, and rhythm pattern. Interval organizations, are prime, second, third, quarter, quint, sixth, seventh, and octave. The organization of melodies, among others: tones, accidental, intervals, melody form, key tones, axial marks, and melodic patterns. The three materials are adapted to the expected learning achievements. Then in order for learning achievements to be achieved, it is important to formulate learning objectives, experiences or learning activities to be done, and subjects each meeting. The learning objectives of Music Dictation are focused on listening skills, identifying, and ultimately skillfully transcribing or representing rhythm sounds, intervals, and melodies using the symbol of notation [14] [P: 8-10].

\subsection{Music Dictation Learning Material Content Level}

Generally, the level of learning material contains facts, concepts, procedures, and principles. The aspect that distinguishes its contents lies in its properties and objectives. The same is the case with the content level of Music Dictation, as follows.

a. Fact. Notes and tones as musical phenomena can be understood, known, and heard only through sounds that are organized according to time and space. Notes are actions in time, relating to the short-lived sounding; Tones are action in space, relating to vibrations that have fixed and different freqwence. A combination of different notes of time will create a beautiful rhythm or rhythm. Similarly, different high-low tones and shorts according to the length of time will produce beautiful melodies. Thus rhythm, interval, and melody are the sounds in the music.

b. Concepts, i.e. all in the form of new understandings that can arise as a result of thought, include definitions, understandings, special characteristics, nature, core /content and so on. The concept of Music Dictation is an activity of listening and identifying rhythms, intervals, and melodies. Then write it down according to the musical elements that built it.

c. Procedures, are systematic or sequential steps in working on an activity and chronology of a. Learning activities of Music Dictation are graded: first, dictation, second, interval dictation; third, melodic dictation. The learning syntax of each section of the Music Dictation topic is: first, i.e .listening; second ,i.e. identifying; third, i.e. transcribing the sound of the rhythm.

d. Principles, namely the main things, principals, and have the most important positions, include evidence, formulas, adagium, postulates, paradigms, theorems, and relationships between concepts that describe the implications of causality. The learning material of The Music Dictation which contains principles is that the elements of music at rhythm, interval, and melody are interconnected. If the wrong automatic rhythm is incorrect on the melody.

\subsection{Principles of Music Dictation Material Development}

Pointing to some of the problems faced by students in music dictation learning activities, syntax that needs to be taken to solfeggio the problem is to first identify and analyze the initial ability of students. The composition of the material should start from the introduction of notes or single tones, then proceed to the introduction of subdivisions of notes or tones. Similarly, the learning experience that begins with rhythm then continues at intervals and melodies [15] [P: 385-386]; [16] [P:3]; [17] [P: 255]; [18] [P: 395-409].

The development of music dictation learning materials that are powerful and successful to use, lecturers are required to understand various aspects related to the development of learning materials, whether related to the nature, function, principles, and procedures of material development and measure their effectiveness. The principles that are the basis in determining the design of music dictation learning materials are conformity, order, continuity, and compactness, aimed at creating quality and effective learning, as follows.

a. Conformity, meaning that learning materials should be relevant to learning achievements in accordance with the standard Indonesian National Qualification Framework (KKNI) formulated on learning objectives, learning experiences, and subjects. The nature of Music Dictation learning achievement is that it is skilled at listening, identifying, and writing rhythm, intervals, and melodies. These three materials are the needs of students used in music transcription and analysis courses.

b. Obedience. Music Dictation learning materials, arranged in tiers, start from the introduction of single notes in the form of basic beats and meters, then the introduction of the notation subdivision [19] [P: 16].

The first level is rhythm material, aimed at providing students with an understanding of the duration of time about notes. Rhythm materials are sorted from easy, medium, to complex levels, as follows.

Basic level: Introduction to notation and basic beats of quarter notes 


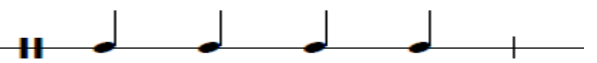

Ground level: Introduction to the eighth-to-eighth subdivision using meter 2

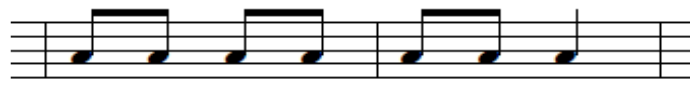

Intermediate level: Introduction to rhythm as a combination of intersection, eighth, and dot notes, using meter 3.

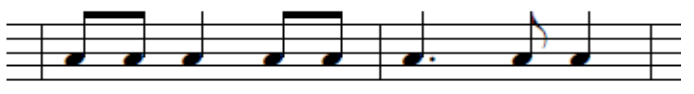

Intermediate level:Introduction of ritem as a combination of intersection and eighth notes, using meter 4.

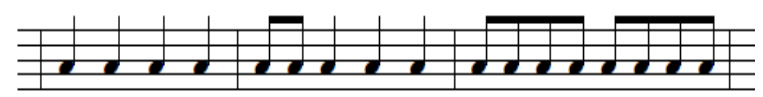

Complex level: Introduction of rhythm as a combination of eighth notes with six-eighths, using meter 4.

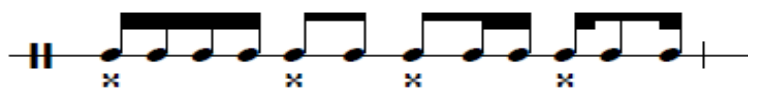

The above rhythm material can be developed in a more varied form by: (a) using compound meter, (b) asymmetric rhythm, (c) rhythm using double note tap unit, (d) using eighth note tap unit, (e) using mark suspension, and (f) using syncopation, and (h) using small and large trill.

The second level is the interval, aiming to provide an understanding of the frequency of tone and the movement of the tone from one tone to another, the motion of stepping up and down jumping up or down. Music Dictation learning materials, arranged in tiers, starting from the introduction of single tones in the form of a tone ladder, then the introduction of tones according to the unit. Manchovy intervals start at close range with ascending motion, descending motion, jumping up, jumping down, using dissonant intervals, as follows.

Basic level: Introduction to Prime intervals

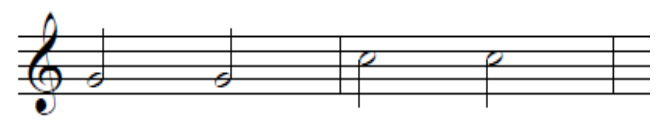

Base level: Introduction to second intervals

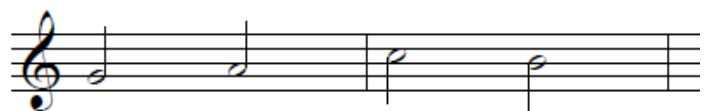

Intermediate level: Introduction to third intervals

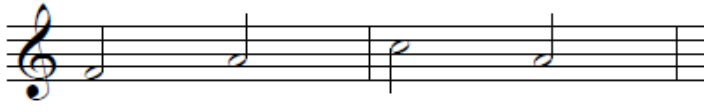

Complex level: Introduction to quarter intervals

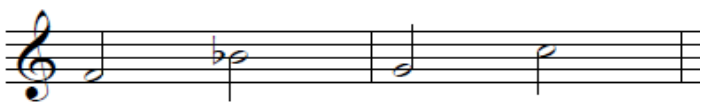

Complex level: Introduction to quint intervals

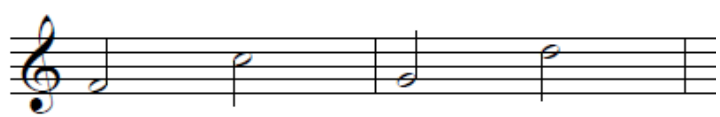

The above interval material can be developed in other forms, namely: (a) diminished intervals, (b) augmented intervals, (c) triton intervals.

The third stage is the development of melodic material, starting from understanding a single melodic line then developed on a subdivision of tones. Such arrangements aim to help students understand the dimensions of time, distance, and space attached to dictated melodic lines. Melodic material sequences start from easy or basic, medium or persistent levels, to complex or difficult.

Basic level: Introduction to melodies with single-tone cross notes, using meter 2 , key $\mathrm{C}$, as follows.

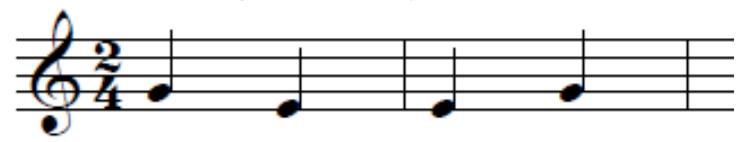

Base level: Introduction to 2-meter melodies, unit of cross-level note beats, using the G key, as follows.

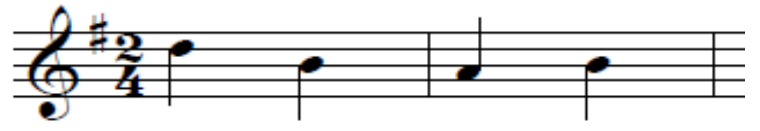

Intermediate level: Melodic recognition with tones is worth half a tap and one tap on meter 2, using the F key, as follows.

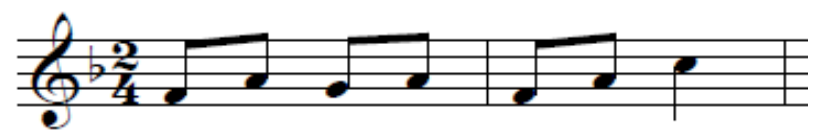

Intermediate level: Melodic recognition with tones is worth half a tap, one tap, and two taps on 3 meters, using the $\mathrm{C}$ key, as follows.

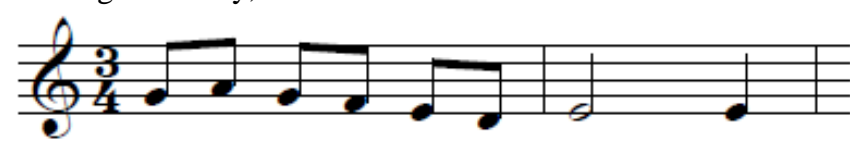

Complex level: Introduction to melodies with single tones, 4 meters high, using the $\mathrm{C}$ key, as follows. 


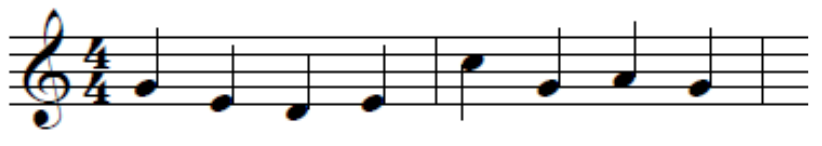

The above melodic material can be developed in other forms by: (a) the melody using compound meters, (b) using the $\mathrm{D}, \mathrm{E}, \mathrm{A}, \mathrm{Eb}, \mathrm{Bb}$, (c) keys using suspension or legato, and (f) using small and large trill.

c. Sustainability, meaning sustainability. Music Dictation learning materials are categorized adequately if they are in accordance with the goals and achievements of learning. In addition, that learning materials are well designed and systemized. Starting from ritem material at the basic level, starting from single tones, naturally keyed C, 2 meters and using intersection notes as a unit of beats (2/4). Furthermore, at the intermediate level, the intersection tones are developed into eight-tone, 3 meters, $\mathrm{G}$ or F. Then continued at a complex level, i.e. the intersection tones are developed into eighth tones, 4 meters, keyed $\mathrm{G}$ or $\mathrm{F}$. The sequence of music dictation learning materials that have been described at the point of order, is a logical and continuous picture of continuity.

d. Integration, meaning integration of various aspects that enable the learning experience can be done by students. Integration music dictation learning materials and their development, based on several things, namely: (1)the academic condition of the student, (2) the student's learning style, (3) relevance to the needs of the student, (4) the profile of the music study program, and (5) the allocation of time. In addition to that consideration, that the three learning materials of The Music Dictation are fully integrated, not fragmentative.

\section{CONCLUSION}

Music Dictation learning materials are one of the important components in learning planning for music study program students in Sendratasik Department of FBS Universitas Negeri Padang, organized according to the characteristics of the course, academic condition of students, goals and expected learning achievements. Music Dictation learning materials, namely ritem, interval, and melody. The principles of development, namely: (a) The principle of conformity, learning materials are adapted to the Curriculum of the Indonesian National Qualification Framework, the karakater of the course, and the needs of students. (b) Principles of order, learning materials, first are ritem; the second is the interval; the third is the melody. (c) The principle of continuity, rhythm material, interval, melody is arranged according to the level, i.e. basic, intermediate, and complex. (d) The principle of integration, that rhythm, intervals, and melodies integrate in its entirety.

\section{REFERENCES}

[1] Sanjaya, Vienna. 2008. Learning Sstem Planning and Design. Jakarta: Kencana

[2] Ornstein, Allan C. \& Hunkins, F.P. 1988. Curriculum: Principles, Foundation and. Englewood Cliffs, NJ: Prantice Hall.

[3] Ardipal. 2010. CTL-Based Music Art Teaching Materials Development Procedure. Imaginary Journal. Journal of Arts and Arts Education. Vol. 8 no. 2.

[4] Wadiyo, Udi Utomo. 2016. Development of Cultural Arts Teaching Materials sub Music Material In Public Schools Elementary Education Level. Journal of Recital Vol. 17 no. 2

[5] Sitimaryam, Dina. 2018. Development of Rhythmic Teaching Materials for Grade 1 Elementary School Students. Journal of Pedadidaktika. Vol. 5 No. 3.

[6] Bogdan, R.C. and Biklen, S.K. 1982. Qualitative Research for Education: An Introduction to Theory and Methods. Boston: Allyn and Bacon, Inc.

[7] Steinback, Susan. 1988. Understanding and Conducting Qualitative Research. IOWA: Kendal/ Hunt Publishing Company.

[8] Moleong, Lexy J. 2012. Qualitative Research Methodology. Bandung: Rosda Karya Youth

[9] Jamalus. 1992. Arts Education 1. Jakarta: Ministry of Education and Culture.

[10] Lumbantoruan, Jagar. 2013. Basic Music Capabilities. Sukabina: Padang

[11] Horvit, M., \& Koozin, T., Nelson, R. 2013. Music for Eartraining. Issue 4. Schirmer Cengage Learning University of Houston

[12] Sumaryanto, Totok. 2005. Effectiveness of The Use of Solfegio Method For Learning Music Playing Skills in Elementary School. Journal of Art Knowledge and Thought. Vol VI no. 2/ May-August 2005. 
[13] Merrit, Justin \& Castro, David. 2016. Comprehensive Aural Skill: A Flexible Approach to Rhythm, Melody, and Harmony. Routledge.

[14] Campbell, Mike. 1998. Sightsinging: The Complete Method For Singing.

[15] Johnstone, Peter. 2013. Teaching Your Improvisation the Pedagogical History of the Jimmy Giuffre 3. International Journal of Music Education. Vol. 31 (4).

[16] Wyatt, Keith, Schroeder, Carl, Elliot, Joe. 2005. Ear Training: For the Contemporary Musician. Hall Leonard: Australia.

[17] McClung, Alan C. 2008. Sightsinging Score of High School Choristers with Extensive Training in Movable Solffege Syllabels your Curwen Hands Signs. Journal of Research in Music Education Vol. 56 Number 3.

[18] Kuo, Yi-Ting \& Chuang, Ming-Chuen. 2013. A Proposal of A Color Music Notation System on A Single melody for Music Beginners. International Journal of Music Education. Vol. 31 (4).

[19] Holmes, John \& Scaife, Nigel. 2015. Aural Training in Practice. The Associated Board of the Royal Schools of Music. 